\title{
A REVIEW OF TWENTY YEARS OF BREAST FEEDING IN LIVERPOOL
}

\author{
BY \\ MARGARET ROBINSON, M.B., L.M., D.P.H. \\ Assistant Medical Officer of Health for the City of Liverpool
}

Spence (1938) in a recent address made the following statement :

'Accurate information about the incidence of breast-feeding is difficult to find, and is still more difficult to compare on account of the difference in the methods of enumeration used. We desire to know what proportion of babies in various countries or in different social groups are breast- or artificially-fed from birth. We desire to know also at what age weaning takes place. It is this precise information which is lacking.'

As medical officer in charge of an infant welfare centre I have endeavoured in this paper to provide some of the information asked for. During the past year I had been impressed by the apparently large proportion of bottle-fed babies seen at the clinic. I thought this might be associated with the fact that breast-fed babies rarely require medical attention. In order to determine whether or not this impression was correct, I noted the feeding in a hundred consecutive cases seeking advice during two weeks in last October, and found that 41 per cent. were breast-fed and 59 per cent. bottle-fed.

While working under several other public health authorities, I had noticed that the incidence of breast-feeding seemed to vary from place to place. It appeared to be lowest in the depressed industrial areas and highest in the rural districts where cows' milk is difficult to obtain owing to the Milk Marketing Schemes, and dried milk can only be procured at the welfare centres, which are necessarily rather scattered. The time of weaning also varied considerably, ranging from nine to eighteen months according to the custom prevailing in the locality.

In an attempt to ascertain if there is any real decline in breast-feeding as has been suggested, the case sheets in the clinic were collected and examined for definite information. The clinic at which I am now working was opened in 1930, and it was decided to begin the investigation on the figures of that year, but later it was found that records for as far back as 1917 could be obtained. A total of 735 cases attended during 1930. Out of these, in 499 the case records were sufficiently complete for working out statistics ; 191 cases ceased attendance during the progress of breast-feeding, and the remaining 45 were also rejected in view of the fact that the babies were either only partly breast-fed 
or the notes were incomplete. Then the records for 1934 were similarly dealt with, the intention being to compare the figures for four-yearly intervals. As the figures for 1938 could not be accurately assessed until all the babies born in that year were nine months old, the year 1937 was taken instead. To complete the four-yearly sequences the figures for 1918, 1922 and 1926 were similarly examined. A certain number of incomplete notes had to be discarded. Owing to the different methods of enumeration used by other workers, it was decided to give two comparative tables for the six years under consideration showing :

(a) The percentage of the babies born each year who were breast-fed during each month of the period of lactation (table 1).

TABLE 1

PERCENTAGE OF BABIES ON THE BREAST DURING THE FIRST EIGHT WEEKS AND SUBSEQUENTLY UP TO THE NINTH MONTH

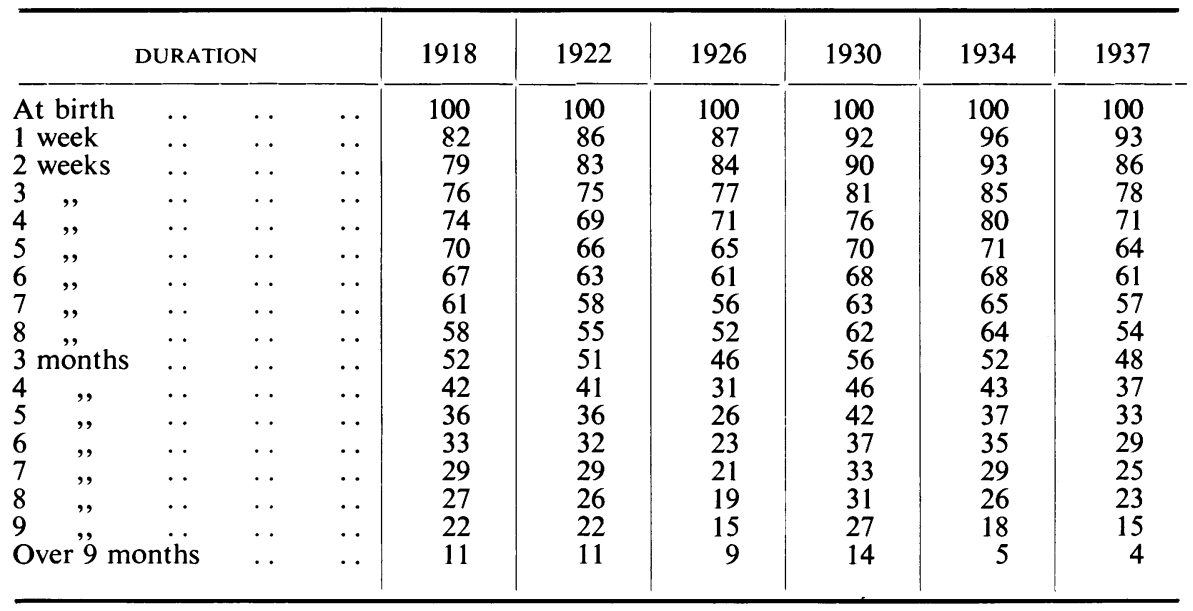

(b) The percentage weaned during each month (table 2). The figures will be slightly lower than those of other investigators because the defaulting and doubtful cases are not included. In addition, the statistics for each year indicate only those babies born in it, and not merely those attending in it. If the latter method had been used, it would have been difficult to assess the results accurately.

The only other investigation of this nature which I could find had been carried out by Garland and Rich (1930) in America. Table 3 shows their results compared with those of Liverpool in 1930.

Fig. 1 shows how the six years coincide, and that the incidence in 1926 is lowest, while that in 1930 is highest. Fig. 2 indicates that there is a tendency in recent years to an increase in breast-feeding during the first, second, fourth and fifth months ; it remains stationary during the third, seventh and eighth months; while from nine months onwards there is a decline. Only three graphs are given, as the others for the same period are similar. I am unable to suggest any reason why in 1930 the incidence should be high and in 1926 


\section{TWENTY YEARS OF BREAST FEEDING IN LIVERPOOL 261}

it should be low. Several different medical officers have been in charge of the clinics. The cases up to 1926 were taken from all the welfare centres in Liverpool, and from 1930 onwards from one centre only. These latter patients are those who were moved out from the old clinic areas to a new housing estate, and are essentially the same social class, but in a new environment.

TABLE 2

THE PERCENTAGE OF BABIES WEANED IN EACH OF THE SIX YEARS UNDER CONSIDERATION IS GIVEN FOR EACH WEEK FOR THE FIRST EIGHT WEEKS, AND FOR EVERY MONTH THEREAFTER UP TO NINE MONTHS. THE NUMBERS UTILIZED AND DISCARDED, AND THE TOTAL NUMBER OF CASE SHEETS OBTAINED FOR EACH YEAR ARE GIVEN BELOW

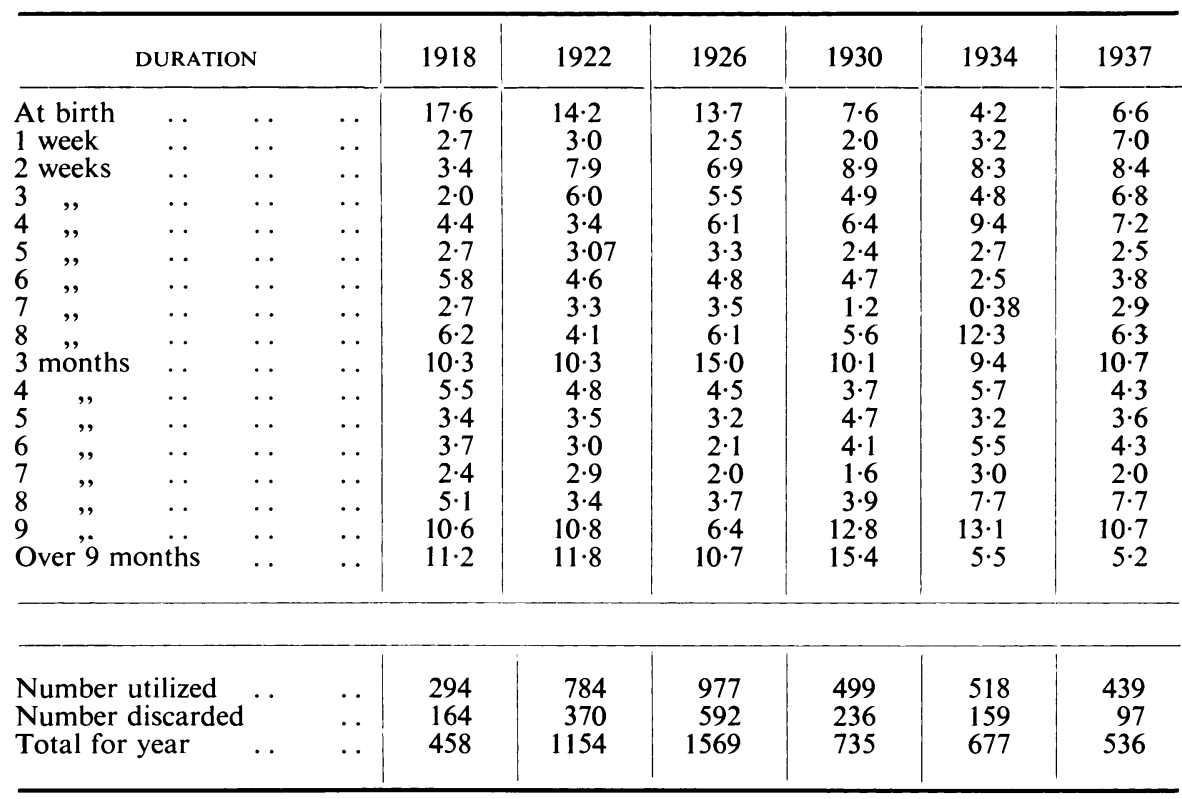

TABLE 3

COMPARISON OF PERCENTAGE OF BABIES WEANED AT VARIOUS AGES

\begin{tabular}{|c|c|c|c|c|c|c|}
\hline & & & & $\begin{array}{l}\text { LIVER POOL, } 1930 \\
\text { (CLINIC) }\end{array}$ & $\begin{array}{l}\text { GARLAND } \\
\text { (CLINIC) }\end{array}$ & $\begin{array}{r}\text { AND RICH, } 1930 \\
\text { (PRIVATE) }\end{array}$ \\
\hline $\begin{array}{l}\text { At birth } \\
1 \text { week } \\
4 \text { weeks } \\
2 \text { months } \\
3 \quad,, \\
4 \quad,, \\
5 \quad,, \\
6 \quad,, \\
8 \quad, \\
1 \text { year } \\
\text { Over } 1 \text { yea }\end{array}$ & $\begin{array}{l}\cdots \\
\ldots \\
\ldots \\
\cdots \\
\cdots \\
\cdots \\
\ldots \\
\ldots \\
\cdots \\
a\end{array}$ & $\begin{array}{l}\cdots \\
\cdots \\
\cdots \\
\cdots \\
\cdots \\
\cdots \\
\cdots \\
\cdots \\
\cdots\end{array}$ & $\begin{array}{l}\cdots \\
\cdots \\
\cdots \\
\cdots \\
\cdots \\
\cdots \\
\cdots \\
\cdots \\
\cdots \\
\cdots\end{array}$ & $\begin{array}{r}0 \cdot 0 \\
9 \cdot 6 \\
20 \cdot 3 \\
15 \cdot 0 \\
10 \cdot 1 \\
3 \cdot 7 \\
4 \cdot 7 \\
4 \cdot 1 \\
5 \cdot 5 \\
25 \cdot 7 \\
1 \cdot 3\end{array}$ & $\begin{array}{r}0 \cdot 0 \\
9 \cdot 0 \\
16 \cdot 0 \\
9 \cdot 0 \\
7 \cdot 5 \\
6 \cdot 0 \\
1 \cdot 0 \\
4 \cdot 5 \\
14 \cdot 5 \\
18 \cdot 0 \\
14 \cdot 5\end{array}$ & $\begin{array}{r}0.0 \\
11.0 \\
15.0 \\
16.5 \\
8.0 \\
10.0 \\
12.5 \\
11.5 \\
10.0 \\
5.5 \\
-\end{array}$ \\
\hline
\end{tabular}




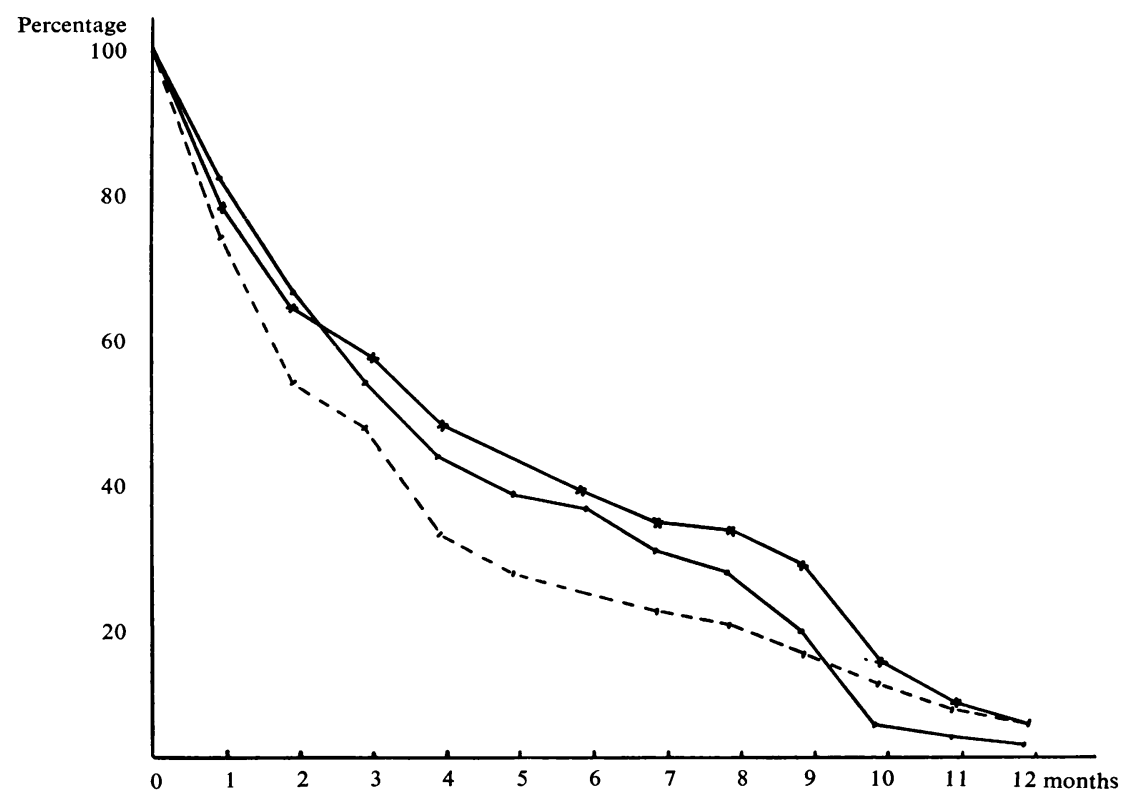

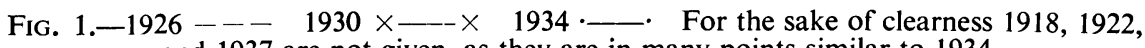
and 1937 are not given, as they are in many points similar to 1934.

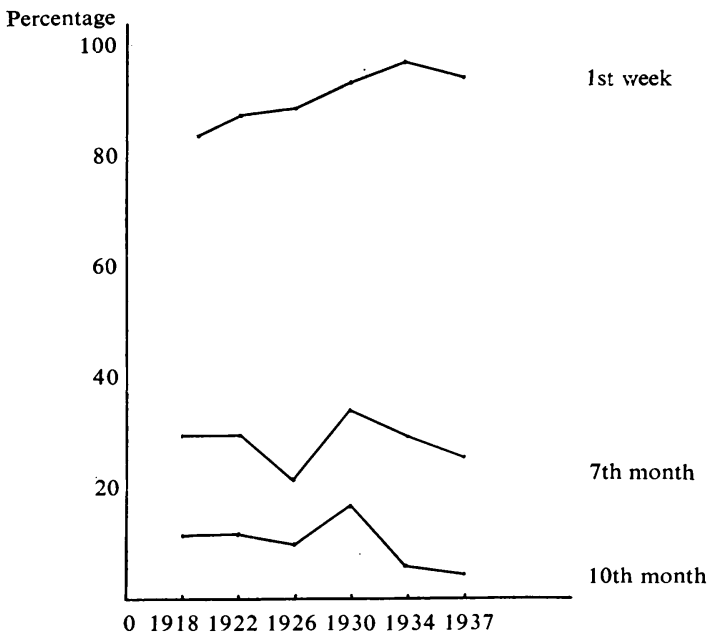

FIG. 2.-Comparing breast-feeding during 1st week, 7 th and 10th months of each year investigated.

There are certain mothers in the district who never attend the clinic, but who are visited in their homes by the health visitors. I thought that there might be a higher rate of breast-feeding among these women and asked one of the health visitors for her records for 1937, which concerned 229 babies. From these the following figures were obtained. 
TWENTY YEARS OF BREAST FEEDING IN LIVERPOOL 263

During the first week 91.3 per cent. were breast-fed ; at the beginning of the second month 62.7 per cent. ; at four months 25.5 per cent. ; at the end of nine months 3.4 per cent. Comparison of these figures with those for the clinic in the same year (1937) shows that they are almost identical.

Therefore it is inaccurate to say that welfare clinics encourage an increase in bottle-feeding.

In 1922 Ida Winternitz came to the conclusion that the capacity for breastfeeding is not hereditary. Table 4 shows her percentages as compared with

TABLE 4

COMPARISON OF THE RESULTS OF AN INVESTIGATION INTO FAMILY HISTORIES : PERCENTAGE OF BREAST-FED BABIES IN VARIOUS GROUPS

\begin{tabular}{|c|c|c|c|c|c|}
\hline AUTHOR & & $\begin{array}{c}\text { AMONG MOTHERS } \\
\text { WHOSE DAUGHTERS } \\
\text { WERE GOOD } \\
\text { NURSES }\end{array}$ & \begin{tabular}{|} 
AMONG MOTHERS \\
WHOSE DAUGHTERS \\
WERE POOR \\
NURSES
\end{tabular} & $\begin{array}{c}\text { AMONG } \\
\text { DAUGHTERS WHOSE } \\
\text { MOTHERS HAD } \\
\text { BREAST FED }\end{array}$ & $\begin{array}{c}\text { AMONG } \\
\text { DAUGHTERS WHOSE } \\
\text { MOTHERS HAD } \\
\text { NOT BREAST FED }\end{array}$ \\
\hline $\begin{array}{l}\text { Bunge } \ldots \\
\text { Winternitz } \\
\text { Robinson }\end{array}$ & $\begin{array}{l}\cdots \\
\cdots \\
\cdots\end{array}$ & $\begin{array}{l}99 \cdot 2 \\
86 \cdot 7 \\
86 \cdot 6\end{array}$ & $\begin{array}{l}43 \cdot 2 \\
91 \cdot 8 \\
65 \cdot 0\end{array}$ & $\begin{array}{l}53 \cdot 2 \\
60 \cdot 8 \\
76 \cdot 4\end{array}$ & $\begin{array}{r}0 \cdot 7 \\
73 \cdot 3 \\
52 \cdot 6\end{array}$ \\
\hline
\end{tabular}

Bunge's and the present series. Mothers are divided by her into two classes. Those who nurse for less than three months are called poor nurses and those who feed for over three months good nurses. The present series was divided in the same manner and consisted of a hundred consecutive new cases (excluding primiparae) who have started attending the clinic since last October. It will be seen that when the mother has breast-fed, three-quarters of the daughters have done likewise ; and when the mother bottle-feeds, about half the daughters do the same. This suggests that parental opinion rather than heredity may play a part in influencing the mother in the method of feeding her child. This surmise is further substantiated by the following data from the 1934 records. It was found in that year that of a hundred mothers living in apartments, 65 per cent. had weaned their babies before the end of two months, compared with a hundred consecutive cases living in houses of whom only 43 per cent. had ceased breast-feeding within the first two months. These cases were further analysed.

100 cases in rooms $\left\{\begin{array}{l}67 \text { primiparae }\left\{\begin{array}{l}20 \text { breast-fed. } \\ 47 \text { weaned before end of two months. }\end{array}\right. \\ 33 \text { multiparae }\left\{\begin{array}{l}17 \text { breast-fed. } \\ 16 \text { weaned before end of two months. }\end{array}\right.\end{array}\right.$

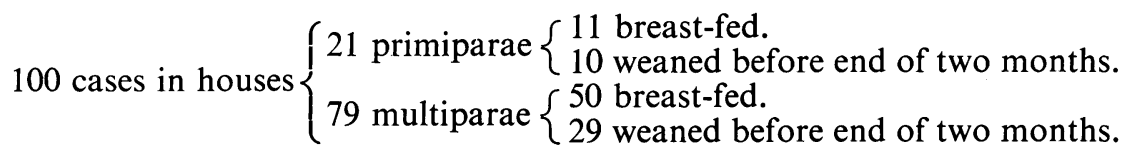

In apartments the other residents object to a crying baby and worry the mother into bottle-feeding. Primiparae are easy to influence and have 
not sufficient experience to resist the well-meant nagging of neighbours and relatives.

\section{Summary}

The case records kept at the Infant Welfare Centres in Liverpool were investigated for every fourth year over the period 1918-1937, and comparative tables and graphs were made in order to discover if there has been any decline in breast-feeding during that time.

The records of one of the health visitor's districts for 1937 for patients who did not attend the clinic were reviewed to determine the breast-feeding rate as compared with that of patients who attended the clinic. No appreciable difference was found.

One hundred family histories have been studied to discover if heredity influences breast-feeding, but no convincing evidence has been found to show that this is the case. On the other hand, there seems definite cause to believe that the influence of close relations and neighbours plays a considerable part in the maintenance of lactation.

The incidence of breast-feeding in mothers living in apartments has been compared with that among mothers occupying houses of their own. A further analysis of these cases shows that primiparae are much more easily influenced by neighbours and relations than are multiparae.

\section{Conclusions}

1. There does not appear to be any real decline in breast-feeding, but there is a shortening of the period of lactation.

2. There is no evidence that clinics cause a rise in the incidence of bottlefeeding.

3. The rate of breast-feeding is higher among women living in houses of their own than among those living in apartments. This is especially evident in primiparae.

4. The capacity for breast-feeding is apparently not hereditary. Parental influence, however, seems to play a part in the maintenance of lactation.

Thanks are due to Dr. W. M. Frazer, Medical Officer of Health for the City of Liverpool, to Dr. R. E. Bell, Senior Assistant Medical Officer in charge of Maternity and Child Welfare Department, for permission to examine the records, and to the health visitors for their kindness in collecting and sorting the case sheets.

\section{REFERENCES}

Bunge, G. v. (1900). Die zunehmende Unfähigkeit der Frauen, München. Garland, J., and Rich, M. B. (1930). New Engl. J. Med., 203, 1279.

Spence, J. C. (1938). Brit. med. J., 2, 729.

Winternitz, I. (1922). Arch. Kinderheilk., 71, 109. 